\title{
Aspectos Sociais e Qualitativos nas Análises de Causas de Acidentes Industriais em Sistemas Tecnológicos Complexos
}

\author{
Carlos Machado de Freitas - Doutor Sc. \\ Marcelo Firpo de Souza Porto, Doutor Sc.
}

Pesquisadores do Centro de Estudos da Saúde do Trabalhador e

Ecologia Humana da Escona Nacional de Saúde Pública da

Fundação Oswaldo Cruz (CESTEH/ENSP/FIOCRUZ)

Rua Leopoldo Bulhõès 1480 - Manguinhos - CEP 21041-210

Rio de Janeiro - RJ; fax (021) 2703219

Palavras chave: análise de acidentes; acidentes industriais; sistemas tecnológicos complexos; indústria química

Key words: accident analysis; industrial accidents, complex technological systems; chemical industry.

\section{RESUMO}

Utilizando como referências contribuições oriundas principalmente das ciências sociais e da ergonomia, o presente artigo visa sistematizar aspectos sociais e qualitativos considerados importantes na análise de causas de acidentes em sistemas tecnológicos complexos, particularmente no contexto das indústrias químicas. A partir da caracterizaçăo dos sistemas tecnológicos e dos seus riscos de acidentes, busca-se demonstrar os limites das técnicas usuais de identificação de perigos e estimativa de probabilidades. Aponta-se para a necessidade de superar as atuais limitaçoes nas análises de causas de acidentes, principalmente em um país como o Brasil, cujas caracteristicas sociais, econômicas e institucionais tornam mais complexa a prevenção e o controle destes riscos industriais.

\section{ABSTRACT}

Using as references some conceptual contributions from social sciences and ergonomics, this article search to systematise social and qualitative aspects which are considered important in the analysis of causes of accidents in complex technol ogical systems with emphasis in the context of chemical industry. The limits of usual methods of risk identification and estimation of probability are showed from the characterisation of complex technological systems and their risks. The necessary overcome accidents analysis is indicated, particularly in countries as Brazil in face of its social, economic and institutional characteristics which make more complex the prevention and control of these industrial risks. 


\section{PRODUÇÃO}

\section{1- Introdução: Na Busca de uma Visão Integradora sobre os Riscos Industriais}

A importância crescente da questão ambiental nas discussóes sobre o diagnóstico de importantes problemas atuais e as possibilidades de alternativas de um novo modelo de desenvolvimento vêm trazendo à tona os limites das abordagens técnico-cientificas voltadas à análise e solução de problemas, marcadas por visões fragmentadas de saberes e compartimentos da realidade. $\mathrm{Na}$ engenharia, notadamente a de produção, o desenvolvimento metodológico recente tende a integrar mais as fases de projetos de produtos e de processos de produção, pautados pelas exigências restritas da qualidade do produto e da redução de custos, através de novas tecnologias tanto ao nível hard (por ex., microeletrônica) quanto soft (novas formas de organização do trabalho). Entretanto, os problemas de saúde e meio ambiente continuam a serem vistos de forma parcial e paralela ao núcleo central do desenvolvimento e gerenciamento de projetos industriais, funcionando eventualmente como elementos de restrição e condição para os especialistas que operam com variáveis tecnológicas e econômicas strictu sensu consideradas mais importantes. (MEIRELLES e MATTOS, 1995).

Segundo Porto (1994), a divisão do trabalho cientifico e profissional pode artificializar a realidade e os fundamentos teórico-metodológicos nos quais se baseiam as várias profissões e abordagens, gerando tensões de vários tipos, tanto na compreensão científica como no exercício das várias especialidades envolvidas com um problema. No caso dos riscos industriais, tais tensões são particularmente críticas, envolvendo a fragmentação disciplinar e profissional. Tal característica propiciou uma certa fragilidade dos conceitos e métodos desenvolvidos nas áreas técnicas ao lidarem com aspectos humanos, sociais $\mathrm{e}$ culturais, gerando um terreno fértil para o surgimento de conceitos e práticas normativas e ideológicas, colocadas como "técnicas" ou científicas ao nível do discurso corporativo.

$\mathrm{Na}$ discussão dos problemas ambientais e de saúde relacionados ao mundo da produção, uma série de fatores vem levando ao que poderíamos denominar como uma tendência à crise $\mathrm{e}$ ruptura da divisão científica-profissional clássica, tanto no interior das corporaçōes técnico-científicas existentes como no surgimento de novas modalidades de conhecimentos científicos e mesmo corporações profissionais. Tal tendência expressa simultaneamente uma crise do conhecimento científico e tecnológico moderno, e um aumento da complexidade dos problemas. Com isso, novas abordagens científicas vem surgindo nas últimas quatro décadas, caracterizando o início de uma nova fase de desenvolvimento que poderiamos denominar de integradora, marcada, ao nosso ver, por algumas características, tais como: 1) rompimento com modelos 


\section{PRODUÇÃO}

monocausais e simplistas de análise e a construção de modelos pautados na multicausalidade; 2) tentativa de integração de aspectos tecnológicos, sociais, econômicos, ecológicos e de saúde nas análises e propostas de intervenção, buscando relacionar abordagens quantitativas e qualitativas; 3) formação de novos centros e áreas de pesquisa, pautados tanto no convivio de equipes multiprofissionais como em abordagens multi- e interdisciplinares; 4) a criação de novas corporações técnico-científicas de origem multiprofissional, adotando modelos sistêmicos e desenvolvendo conceitos interdisciplinares; 5) a definição de objetos e seleção de métodos científicos de trabalho inseridos em contextos sociais e institucionais voltados à discussão e solução de problemas especificos, e não por recortes definidos pela divisão clássica do conhecimento científico (GARCIA, 1994).

\section{Como exemplo claro deste} movimento, ao nível da relação produção, trabalho e saúde, citamos as contribuiçð̃es das ciências sociais e humanas nas orientações recentes da Ergonomia, da área de Análise e Gerênciamento de Riscos (Risk Analysis), e da área de Saúde dos Trabalhadores na Saúde Pública latino-americana. Mas esta tendência à integração não faz parte somente de certos setores do conhecimento científico, expressando uma necessidade mais global de serem reestruturadas as atuais bases da própria ciência. Para autores como Funtowicz e Ravetz (1994), a complexidade e $\mathrm{a}$ urgência dos problemas ambientais colocam a necessidade de criação de uma nova prática científica, onde a ciência seja reconhecedora de seus limites e capaz de dialogar com outras fontes de saber e valores, ultrapassando as atuais metas de buscar verdades instrumentais e conquistar a natureza, para fundar-se na necessidade de uma nova relação harmoniosa entre homem e natureza.

O presente artigo busca sistematizar algumas das contribuições advindas das Ciências Sociais e da Ergonomia, onde aspectos sociais e qualitativos são introduzidos na análise de causas de acidentes em sistemas tecnológicos complexos, com ênfase na indústria química (incluindo petroquímicas e petroleiras) e no problema dos acidentes químicos ampliados (FREITAS, PORTO e GOMEZ, 1995). Esta questão parece ser especialmente relevante no contexto brasileiro, onde existe um agravamento sócio-político destes acidentes (PORTO and FREITAS, 1996) frente às características sociais, econômicas e institucionais que fragilizam nossa sociedade no enfrentamento destes riscos industriais. Compreendê-las e de modo mais abrangente torna-se extremamente importante, pois pode resultar, ao final, no desenvolvimento de estratégias de gerenciamento de riscos mais adequadas ao problema.

\section{2- A Noção de Sistemas Tecnológicos Complexos no Contexto da Indústria Química}

A noção de sistemas tecnológicos complexos - envolvendo relações nãolineares - foi desenvolvida por Perrow 


\section{PRODUÇÃO}

(1984), que em seu livro Normal Accidents tenta explicar as dificuldades e incertezas envolvidas na análise e gerenciamento de riscos em setores como $a$ indústria nuclear e química, sendo esta última por nós privilegiada neste artigo. A atenção sobre as indústrias de transformação química em que predominam sistemas de interações nãolineares, reside no fato de terem sido o locus de muitos acidentes graves já registrados. (FREITAS, 1996).

A indústria química possui um universo bastante heterogêneo e de dificil classificação, sendo, segundo Haguenauer (1986), composta por indústrias básicas de elementos químicos e petroquímicas e indústrias finais. Diversas indústrias de transformação quimica caracterizam-se por possuirem sistemas tecnológicos de interações não-lineares, através de processos contínuos de fabricação que integram as várias unidades produtivas presentes na planta industrial. (HAGUENAUER, 1986; PERROW, 1984). Segundo Perrow (1984), os riscos nestas indústrias são fortemente determinados pela sua própria dinâmica técnica e organizacional.

Nas indústrias em que predominam interações não-lineares, as partes, unidades ou subsistemas servem a múltiplas funções, constituindo sistemas tecnológicos de interações não-lineares. Um aquecedor tanto pode aquecer o gás no tanque A como também ser utilizado para absorver o calor excessivo do reator químico. Se o aquecedor falhar, o tanque
A será muito resfriado e comprometerá a reação quimica esperada; ao mesmo tempo, o reator químico será sobreaquecido, na medida em que o calor não é absorvido. Como observa Perrow (1984), esse aquecedor tem a vantagem de economizar energia, porém, se falha, tanto o aquecimento do tanque $A$ como o resfriamento do reator falham, sendo isso mais complexo do que nas interações lineares.

Para Perrow (1984), essas interações não-lineares são interações complexas, pois não são somente adjacentes ou seriais, como as lineares, mas podem multiplicarse à medida que outras partes, unidades ou subsistemas dos sistemas tecnológicos sejam atingidos. Com o objetivo de melhor demonstrar esses argumentos do autor, tome-se um outro exemplo que ele fornece sobre uma indústria química. Nesse exemplo, convida a imaginar uma planta química onde é esperado que, por conta da pressão que é mantida mais alta no tanque A, flua desse tanque para outro B um determinado gás básico. Além desse gás básico, vários outros elementos, como reagentes ou gases inertes, vão do tanque A para o B, alterando ainda mais a mistura. Essa forma de interação é completamente direta e linear.

O autor observa, porém, que existe o perigo de essa interação tornar-se nãolinear. Pode ocorrer reversão circular se a pressão no tanque $\mathrm{A}$ declinar por causa de falha no mesmo ou em qualquer outra parte, unidade ou subsistema do sistema tecnológico. A queda de pressão no 


\section{PRODUÇÃO}

tanque $\mathrm{A}$ faz com que o gás básico, que dele fluia para o $B$, agora retorne para o tanque A. Conscientes desse perigo, os engenheiros que projetam o sistema incluem uma válvula de segurança que pode ser colocada entre os dois tanques, a fim de garantir que of fluxo permaneça em apenas uma direção e mantenha o sistema tão linear quanto possivel. Válvulas, entretanto, podem falhar, sobretudo quando são raramente utilizadas. Se a pressão no tanque $\mathrm{A}$ cai e a válvula de segurança falha, a reversão circular será novamente possivel, e os operadores podem não esperar ou não estar preparados para esse tipo de interação. Perrow (1984) considera esse exemplo bastante simples, de modo que muitos operadores acreditarão ser possivel esse tipo de interação não planejada. Porém, chama a atenção para o fato de que as interações não-lineares complexas são geralmente aquelas não esperadas no projeto do sistema tecnológico. E, mesmo quando são esperadas, podem, pelo fato de raramente ser ativadas, acabar sendo esquecidas pelos operadores ou projetistas.

Além do mais, é importante observar que, em sistemas tecnológicos com grau elevado de complexidade, a queda de pressão no tanque $A$ pode afetar não somente o tanque $B$, mas também as unidades ou subsistemas C, D e E. Quando o componente em que ocorre a falha pode interagir com um ou mais componentes na seqüência normal da produção, seja essa interação projetada ou não, o resultado são interações complexas, não-lineares. Essa característica dos sistemas tecnológicos com interações nãolineares faz com que muitas das interações não sejam imediatamente perceptíveis, tornando-se invisiveis para os operadores, pois os eventos ocorrem dentro de partes, unidades ou subsistemas das indústrias, como tanques ou computadores, por exemplo.

A complexidade das interações nãolineares nesses tipos de sistemas tecnológicos demanda a necessidade de aumentar o número de controles que devem ser instalados e monitorados, pois muitos dos componentes são interligados por meio de várias ramificações ou reversibilidades circulares, de modo que grande parte das interações não é imediatamente visivel e compreensível pelos operadores. Continuamente são feitas tentativas de redução no número de controles pela automação das interações subsidiárias, deixando apenas os principais parâmetros para os operadores se preocuparem, procurando assim facilitar e reduzir o tempo de suas ações em caso de falhas. Entretanto, esse processo de redução do número de controles diminui a flexibilidade do sistema; o operador perde a habilidade de corrigir falhas menores em uma parte, pois não pode sair do alto nível de complexidade para o baixo nivel, de modo a agir apenas sobre partes únicas e, assim, corrigir a falha a tempo.

Em resumo, para Perrow (1984), o que caracteriza os sistemas tecnológicos complexos com interações não-lineares é a ligação entre as partes ou unidades que 
estão na seqüência da produção, o que faz com que haja muitos modos comuns de conexões entre os componentes (partes, unidades ou subsistemas). Essa característica de muitas conexões, nas quais os componentes estão altamente acoplados, possibilita reversibilidades circulares não familiares e indesejáveis em casos de falhas, resultando inevitavelmente em múltiplas e inesperadas interações, em que o controle se dá por meio de informações indiretas e inferências, limitando a compreensão de alguns processos de falhas e das ações imediatas no sentido de interromper seu desenvolvimento. Esses são os elementos básicos que compõem o que Perrow (1984) denomina acidente normal, cuja essência inclui a interação de múltiplas falhas que não estão em sequiência operacional direta e certo grau de incompreensibilidade das mesmas, o que é relativamente freqüente em sistemas tecnológicos complexos.

Exemplo típico desse tipo de acidente foi o ocorrido na usina nuclear de Three Mile Island, nos E.U.A., em 1979: em apenas 13 segundos, houve três falhas que interagiram, tornando impossivel aos operadores fazerem seu diagnóstico a tempo. Só oito minutos depois, quando muitos dos danos já haviam sido iniciados e os operadores se encontravam confusos com as alterações na performance da planta, é que se iniciaram as ações no sentido de parar o desenvolvimento das falhas e dos danos (Perrow, 1984; Wisner, 1994). Esse acidente, assim como outros analisados por aqueles autores, evidencia as dificuldades de interpretação das interações não-lineares complexas resultantes de falhas raras no sistema tecnológico, ultrapassando a capacidade de integração do cérebro humano, pelo menos dentro dos prazos exigidos para tomadas de decisões e realização de ações para interromper o desenvolvimento das falhas no processo de produção.

\section{3- Limites e Incertezas nas Etapas de Identificação dos Perigos e Estimativa de Probabilidades de Acidentes em Sistemas Tecnológicos
Complexos}

$\mathrm{Na}$ etapa de identificação dos perigos, os modelos de determinação de probabilidade dos diferentes modos de falhas nos componentes que poderiam levar à ocorrência de acidentes químicos ampliados são, de modo geral, construídos a partir da identificação de possíveis eventos ou falhas anteriores. Nas indústrias de processos de transformação química, porém, e principalmente nas multinacionais que produzem elementos químicos e operam no limite da ciência e da tecnologia, a obtenção de dados históricos suficientes sobre modos de falhas nos componentes é inviabilizada por sua grande capacidade inovadora, $o$ que é inerente à sua própria dinâmica de inserção no mercado mundial. Como observam Mandl et al. (1983), essa é uma das questões mais dificeis para as análises técnicas de riscos, pois, nesses casos, os especialistas são obrigados a construir 


\section{PRODUÇÃO}

seus modelos a partir de dados de outros sistemas tecnológicos presumivelmente similares, aumentando a incerteza dos resultados, o que frequentemente não é explicitado. A ignorância é justamente um dos maiores problemas destes modelos, ou seja, quando não se sabe o que não se sabe. (Wynne, 1987)

$\mathrm{Na}$ técnica HAZOP (Hazard and Operability Studies) de identificação de perigos, a busca estruturada de possiveis causas de desvios em variáveis do processo industrial, como temperatura, pressão, vazão e composição em diferentes pontos do sistema tecnológico, se dá a partir de perguntas sobre determinadas palavraschave. Entretanto, inevitavelmente, a escolha das palavras-chave será bastante influenciada por um modo de raciocinio de interações lineares e pelos dados históricos disponiveis sobre causas e desvios que provocaram falhas passadas. De acordo com Perrow (1984), na reconstrução de muitos acidentes ampliados, encontram-se como causas a banalidade e a trivialidade. Nas indústrias de transformação química, a complexidade dos sistemas tecnológicos e o fato de os componentes serem altamente acoplados contribuem para que pequenas falhas se propaguem de maneira inesperada. Como observa o autor, basta que um a pequena falna $X$ ocorra exatamente num momento em que $Y$ não esteja funcionando bem para que as duas falhas interajam e, simultaneamente, iniciem um incêndio e silenciem o alarme. Se essa interação jamais ocorreu, se jamais foi esperada no projeto do sistema tecnológico, dificilmente fará parte das questões que orientam a busca estruturada da identificação de causas de acidentes na técnica HAZOP.

Esses limites também se estendem à outra técnica de identificação de perigos, como a FMEA (Failure Modes and Effects Analysis), que tem como principio olhar isoladamente tanto as falhas nos componentes como as falhas humanas que possam afetar o funcionamento do sistema tecnológico. O conjunto de questões que orientam essas técnicas de identificação de perigos, e que na verdade se limitam apenas a uma parte do universo que está sendo considerado, acaba por direcionar os resultados só para pequenos segmentos dos sistemas tecnológicos envolvidos (LINNEROOTH, 1983). O processo de identificação de perigos nas análises técnicas de riscos de acidentes, além de ser inevitavelmente seletivo ao escolher as questões que devem ser focalizadas, tende também a congelar o contexto em que está sendo realizado (WYNNE, 1987). Essas características fazem com que o modo como os problemas são definidos e colocados possa, frequientemente, conduzir a resultados diferentes para a mesma questão (KUNREUTHER and LINNEROOTH, 1983).

Uma das grandes desvantagens da abordagem da engenharia é, ao privilegiar fatores quantificáveis e interações relativamente simplistas, negligenciar importantes fontes não técnicas e não quantificáveis de conhecimento, 


\section{PRODUÇÃO}

resultando isso de uma definição bastante restrita de riscos. No exemplo clássico da análise de riscos realizada no complexo petroquímico de Rijmond, entre 1979 e 1981 (Holanda), a redução dos 14.000 cenários de falhas encontrados foi reduzido à um pequeno número de classes de possibilidades similares de modo a permitir uma análise mais detalhada das probabilidades. Porém, esta redução não necessariamente diminuiu as incertezas sobre os riscos presentes no sistema tecnológico em questão (RENN, 1985).

Se nas etapas de identificação de perigos - as primeiras a serem realizadas em uma análise completa de riscos de acidentes - já se encontra uma série de limitações, é de esperar que elas se estendam às outras etapas, como nas estimativas probabilísticas dos modos de falhas e consequiências pelos métodos de AF (Árvore de Falhas) e AE (Árvore de Eventos) (ver Figura I). Wynne (1987) chama a atenção para o fato de os eventos iniciais identificados como pontos de partida dos acidentes na AF, cujas probabilidades são estimadas, serem o resultado de escolhas obscurecidas pelos métodos estatísticos, pois pesos diferenciados são atribuídos às variáveis em questão. Além do mais, sua formalização em uma árvore sugere que toda a sequiência de causa-efeito pode ser apreendida pelas variáveis binárias $\mathrm{OU}$ e E (AF), SIM e NÃO (AE). Entretanto, Wynne (1987) observa que o processo real de produção é bem mais complexo, de modo que falhas parciais ocorrem sem que sejam apreendidas por meio de $\mathbf{O U}$ e $\mathbf{E}$,
SIM e NÃo. Uma válvula pode não estar nem aberta, nem fechada, porém mais ou menos aberta ou fechada. Uma bomba pode não estar parada e nem em completo funcionamento, mas operando de maneira intermitente ou abaixo de sua capacidade esperada. Wynne (1987) considera que a técnica de multiplicar cadeias de probabilidades e integrá-las em cadeias convergentes dissimula o fato de que diferentes espécies de processos e incertezas relacionadas podem estar envolvidas em rotas separadas para determinados pontos finais dados, tanto pela diversidade das formas de olhar e colocar os problemas como pela disponibilidade de dados históricos e similares sobre falhas e conseqüências anteriores.

\section{4- 0 Modo Degrado de Produção e as Anormalidades Normais}

A imagem pública dos sistemas tecnológicos complexos é a de que, a partir de regras racionais universais e descontextualizadas bem estabelecidas, seu funcionamento é permanentemente seguro, e as falhas, esporádicas e ocasionais. Quanto mais longe se está do chão da fábrica, mais provável é que se considerem as falhas humanas e/ou de componentes fatores causais de um acidente. Porém, como observa Dwyer (1991), à medida que se aproxima do chão da fábrica, o que se encontra como causas dos acidentes são fatores bastante tangíveis. Essa proximidade revela que 
as falhas, principalmente as parciais, são bem mais freqüentes, fazendo parte do funcionamento normal dos sistemas tecnológicos. Descobre-se que a implementação dos projetos ou das atividades de operações são o resultado contínuo da invenção e negociação de novas regras e inter-relações sociais, em que a adaptação aos fatores locais do contexto em que se situam ocorre de modo ad hoc ou mediante o exercicio do poder para adaptar as situações locais às "necessidades" dos princípios tecnológicos gerais (WYNNE, 1988).

Esse contínuo processo de invenção e negociação de novas regras e interrelações nos sistemas tecnológicos, como no caso das indústrias de transformação química e processo contínuo, contribui para ampliar a grande variabilidade a eles inerente. Segundo Daniellou (1986), essa variabilidade é constituída por fatores como "...a alternância do dia e da noite, a presença ou absenteísmo do pessoal de dia, as manobras imprevistas, as mudanças de programação, as variações na qualidade da matéria-prima, as variações imprevisíveis, como as quedas de tensão elétrica, as falhas de equipamentos e ainda a interconexão entre diferentes processos ou subsistemas de um mesmo processo..." (Apud: Duarte, 1994) - Ao longo do tempo, processos sociais, econômicos, ambientais e técnicos da operação dos sistemas tecnológicos contribuem para sua deterioração, constituindo, assim, um modo degradado de operação e ampliando ainda mais a variabilidade a eles inerente (Duarte,
1994). No modo real de operação dos sistemas tecnológicos, a amplificação da variabilidade e o modo degradado de operação vão constituindo seu modo normal de operação, a segurança vai pouco a pouco sendo minada pela banalização de falhas consideradas "menores", constituindo o que Wynne (1988) denomina anormalidade normal. A grande variabilidade desses sistemas tecnológicos complexos e seu modo degradado de operação, que continuamente transforma a anormalidade em normalidade, sendo esse seu modo real e normal de operação, transformam falhas visiveis em invisiveis, tornando sua captura algumas vezes dificil por técnicas como a $\mathrm{AF}$ e a $\mathrm{AE}$, pois grande parte das análises técnicas de riscos são muito mais baseadas no modo prescrito de operação dos sistemas tecnológicos do que no seu modo real de operação (PORTO, 1994; DUARTE, 1994).

Wynne (1988) chama a atenção para o fato de que até que um acidente ocorra, as incertezas sobre os riscos são periféricas, e a imagem pública que se tem é de que tudo está sob controle, que o projeto tecnológico e os procedimentos operacionais são rigorosamente checados e mantidos sob permanente supervisão. Após ocorrer o impensável, entretanto, as investigações, quando realizadas adequadamente, permitem vislumbrar um mundo em que regras e a rotina de segurança dos sistemas tecnológicos são bem menos controladas, os procedimentos da operação real diferem daqueles 
prescritos e nem tudo é permanentemente checado e supervisionado.

\section{Muitos acidentes ocorridos} recentemente na indústria química em paises como Índia - caso de Bhopal, o maior acidente industrial em termos de vítimas imediatas - e Brasil vêm demonstrando os limites inerentes às etapas de identificação dos perigos e de estimação das probabilidades em indústrias de transformação química que operam com sistemas tecnológicos complexos, principalmente quando à estes acoplam-se aspectos sociais e econômicos que agravam não somente o potencial de ocorrência como também de gravidade em paises de industrialização recente e periférica (FREITAS, 1996; PORTO and FREITAS, 1996). Como observa Wynne (1988), esses eventos constituem-se em uma espécie de fratura exposta dos sistemas tecnológicos. Permite-nos vislumbrar um universo pouco acessivel em "situações normais", revelando um modo degradado de produção em que as anormalidades permanentemente se convertem em normalidades.

\section{A Necessidade de Superar os Atuais Limites nas Análises de Causas de Acidentes}

O principal problema nas técnicas frequentemente empregadas na engenharia para a análise de riscos de acidentes é que muitas vezes partem de uma imagem dos sistemas tecnológicos que, na prática, não condiz com a realidade do seu dia-a-dia de operação. Esses sistemas não são apenas tecnológicos, compostos de válvulas, linhas de transferência, reatores e tanques de armazenamento, operando dentro de uma racionalidade técnica e unitária (WYNNE, 1987); são também sociais, reproduzindo, no pequeno universo das plantas industriais, relações sociais presentes na sociedade (FREITAS, 1996). Assim, os acidentes não podem ser vistos como resultados de falhas apenas tecnológicas e humanas, mas também, e em última análise, falhas gerenciais e organizacionais que permeiam as relações sociais no trabalho e o modo de operação dos sistemas tecnológicos. É considerando essas características, simultaneamente tecnológicas e sociais, que Wynne (1987 e 1988) propõe o conceito de tecnologia como redes técnicoorganizacionais ou sociotécnicas. O que Wynne (1987) pretende com esse conceito é chamar a atenção para o fato de que os analistas não podem desconsiderar a inevitável e mútua interação do tecnológico com o social na configuração de situações de riscos de acidentes ou sua ocorrência. Interação que não se restringe ao nível da operação dos sistemas, mas se estende à própria ótica dos analistas de riscos, que, além do conhecimento técnico, incorporam em suas análises julgamentos informais e inadvertidos sobre os sistemas geradores de riscos de acidentes, refletindo os conflitos estruturais tanto do conhecimento 
científico como das perspectivas institucionais às quais estão relacionados.

As interações entre o tecnológico e o social na geração de acidentes e suas análises levam à concordância com a afirmação de Kunnreuther (1983), para quem estes não podem ser consideradas no vácuo, devendo ser examinados no contexto social e político em que se encontram. No caso de países como o Brasil, que ocupa um papel periférico aos grandes centros mundiais de produção de produtos químicos, a compreensão deste contexto é de extrema importância, pois muitas vezes as análises de causas de acidentes, tanto prospectivas como restrospectivas, acabam tendo o papel de formular muito mais estratégias de controle das relações sociais de trabalho pelas empresas do que um efetivo gerenciamento dos riscos. O resultado é que os próprios trabalhadores acabam sendo na maioria das vezes responsabilizados pelos acidentes, sendo considerados culpados até que se prove $o$ contrário, como parte de uma estratégia de gerenciamento artificial de riscos (MACHADO e GOMEZ, 1995).

A questão é que a responsabilização dos trabalhadores pelos acidentes em que muitas vezes se transformam em vitimas, revela o paradoxo do papel das organizações e do gerenciamento de riscos na prevenção - ou causa - de falhas de sistemas tecnológicos de alto risco, como as indústrias quimicas. Perrow (1984) observa que esses sistemas tecnológicos, tendo muitas de suas falhas não visiveis e imediatamente compreensíveis, acabam por exigir dos operadores que sejam capazes de, em determinadas situações, agir de modo independente e criativo. Mas, pelo fato de esses sistemas tecnológicos serem altamente acoplados, o controle dos operadores deve ser centralizado, uma vez que não há tempo para checar cada coisa e estar consciente do que outra parte do sistema está realizando. $O$ operador não deve agir de acordo com seu pensamento ou instinto, pois altamente acoplado significa passos altamente prescritos e seqüências invariảveis, que não podem ser alteradas. Sistemas, porém, não podem ser simultaneamente descentralizados e centralizados. Ao optarem por responsabilizar o operador e não aceitarem a tomada de atitudes não previamente prescritas, ainda que elas possam em alguns casos reduzir os riscos, como se verifica em alguns acidentes, as organizações e seu gerenciamento estão procurando manter a estrutura de poder interna altamente centralizada e hierarquizada. Evitar o que consideram riscos para essas estruturas de poder tornase muitas vezes mais importante do que evitar os riscos para a saúde e o meio ambiente.

Como observa Perrow (1984), o risco de acidentes nunca será completamente eliminado dos sistemas tecnológicos complexos e de alto risco, como as indústrias químicas e nucleares, de modo que no mínimo, deve-se parar de responsabilizar pessoas e fatores causais errados, além de considerar os sistemas 
fixos, pois, na prática, isso os torna ainda mais perigosos. Quando Perrow publicou seu livro, em 1984, identificou que entre $60 \%$ e $80 \%$ das análises técnicas de acidentes tendiam a identificar a falha do operador entre os principais fatores causais de acidentes. Cerca de 10 anos depois, Wisner (1994) registra que essa tendência vem sendo revertida pelo reconhecimento de que, na verdade, atribuir a responsabilidade das causas dos acidentes aos operadores é forma relevante de simplificação nas análises.

A análise de 121 acidentes químicos ampliados registrados no Major Accidentes Reporting System (MARS) das Comunidades Européias entre $1980 \mathrm{e}$ 1991, por meio das Tabelas I, II, III e IV, elaboradas por Drogaris (1993), revela essa tendência apontada por Wisner (1994). Na Tabela I, pode-se verificar que $28(23 \%)$ dos acidentes tiveram suas causas imediatas atribuidas a falhas dos operadores, e 54 (45\%) a falhas nos componentes. Observando as causas subjacentes desses acidentes (ver Tabela II), verifica-se que 88 ( $73 \%$ ) foram atribuidas a omissões gerenciais/ organizacionais e 65 (54\%) a inadequabilidades dos projetos. Dos 54 acidentes em que falhas nos componentes foram identificadas como causas imediatas (ver Tabela III), 44 (81\%) tiveram como causas subjacentes omissões gerenciais/organizacionais e 37 (69\%) inadequabilidades dos projetos. Dos 28 acidentes cujas causas imediatas foram os erros dos operadores (ver Tabela IV), verifica-se que os 21 relacionados às atividades de operação tiveram como causas subjacentes ausência de cultura de segurança $(20 \%)$, procedimentos insuficientes e não claros (71\%), supervisão insuficiente $(24 \%)$, treinamento insuficiente $(24 \%)$ e outras deficiências relacionadas ao projeto (71\%). Quanto aos sete relacionados às atividades de manutenção (ver Tabela V), a totalidade das causas subjacentes se deveu a procedimentos insuficientes e não claros.

A análise das tabelas do MARS revela a tendência apontada por Wisner (1994), pelo menos na Europa, de não se buscarem nas falhas dos operadores os únicos e principais fatores causais dos acidentes. Mesmo nos acidentes em que as causas imediatas foram atribuidas a falhas nos componentes ou dos operadores, análises posteriores e mais detalhadas identificaram como principais causas subjacentes as omissões gerenciais/ organizacionais e as inadequabilidades dos projetos. Com relação à realidade brasileira, entretanto, o que se verifica ć a responsabilização dos próprios trabalhadores pelos acidentes em que estão envolvidos como prática comum. Exemplo paradigmático disto pode ser observado na Tabela $V$, reproduzida de um relatório de investigação de acidentes (alguns fatais) elaborado para subsidiar um inquérito civil público conduzido pelo Ministério Público do Trabalho (1995) em uma grande empresa multinacional alemã do ramo químico, a qual vende permanentemente a imagem de ser uma das que mais investe em proteção 
ambiental e segurança. $O$ que a Tabela $\mathrm{V}$ revela é que a atribuição da causa dos acidentes à falhas dos operadores, particularmente falta de hábito em segurança, é uma prática sistemática nesta multinacional, não condizendo com os métodos de investigação de acidentes que vem sendo realizadas nas Comunidades Européias e que buscam suas causas subjacentes, demonstrando um duplo padrão na busca e interpretação das causas de acidentes. O problema é que esse tipo de análise, que em sua quase totalidade responsabiliza o próprio trabalhador pelo acidente, não se restringe à empresa multinacional em questão, sendo uma prática ainda muito comum em indústrias no Brasil. Esse tipo de análise de causas de acidentes contribui para que, por razões de manutenção das estruturas internas de poder, as empresas que se situam no Brasil enfoquem o problema de uma maneira que contribui para uma forma de gerenciamento de riscos que é, ela mesma, tão perigosa quanto os produtos manipulados e produzidos.

Como observam Paté-Cornell e Bea (1992), boa parte das análises de riscos de acidentes partem dos pressupostos de que não existem falhas no projeto tecnológico, de que a construção foi realizada de acordo com os planos, de que os procedimentos de operação são adequados. As análises de acidentes passados, que servem de base para as etapas de identificação de perigos e estimativas de probabilidades, ao revelarem que os sistemas não são apenas tecnológicos e que as dimensões sociais se encontram presentes no seu modo real de operação, são de extrema importância para o deslocamento do gerenciamento artificial dos riscos (MACHADO, 1991) para o efetivo gerenciamento dos riscos. Responsabilizar as vítimas sugere uma desagradável - e talvez consciente - classe de viés, já que, muitas vezes, o modo real de operação requer que os operadores ignorem as precauções de segurança visando à alta produção, ao cumprimento dos prazos estabelecidos e à manutenção de seu emprego (PERROW, 1984). Porém, quando ocorre um acidente e operadores morrem ou são lesionados, considera-se que foi por falhas suas que 0 mesmo aconteceu. Mudar o foco de análise, considerando o modo real de operação e o papel da organização e do gerenciamento nesse processo - $o$ que obriga a ir além da imagem dominante do funcionamento dos sistemas tecnológicos - não deve significar simplesmente a inversão na identificação de responsabilidades.

Para que as análises de riscos aproximem-se do modo real de operação das indústrias de transformação química e se convertam num instrumento capaz de efetivamente apontar medidas de gerenciamento e redução de riscos que vão além daquelas puramente técnicas, a melhoria nas relações sociais de trabalho deve ser considerada de grande importância (DWYER, 1991). Relações sociais de trabalho que possibilitem, entre outras coisas, a efetiva incorporação da participação nas análises de riscos de acidentes e na formulação de estratégias 
de gerenciamento daqueles que vivenciam no dia-a-dia o modo real de operação, a fim de possibilitar mudanças gerenciais e melhorias organizacionais que garantam que a busca de lucro de uma indústria não resulte em incentivos diretos ao corte nas atividades de manutenção e ao negligenciamento dos procedimentos de segurança no setor de produção (PATÉCORNELL, 1993).

\section{Conclusão}

Em sistemas tecnológicos complexos, como indústrias químicas de transformação, a aceitabilidade dos riscos e os critérios de segurança para sua operação são um contínuo processo de negociação e invenção de novas regras e relaçðes sociais. Sem dúvida, falhas humanas e nos componentes existem, mas inseridas num universo em que a tecnologia e as relações sociais interagem dinamicamente, tornando-se impossível, sem incorrermos em reducionismos limitantes, tanto considerá-las isoladas como abstrai-las da forma como são gerenciados a produção e os riscos.

$\mathrm{Na}$ operação desses sistemas tecnológicos, para que a produção ocorra nos volumes e prazos programados, o que muitas vezes se encontra é uma série de transformações no modo prescrito de operação do projeto original. automático é transformado em manual, o contínuo em intermitente, e a adaptação dos trabalhadores ao modo degradado de operação faz-se pelo exercício do poder. Esse processo vai, ao longo do tempo, conduzindo a um inadequado controle sobre todo o processo de produção e a condições de trabalho perigosas, minando a segurança com a banalização das falhas, que passam a ser consideradas menores e "normais". Uma análise de causas de acidentes que desconsidere esses aspectos, presentes na origem de muitos, estará sendo orientada para uma forma artificial e desumana de gerenciamento. Projetos de sistemas tecnológicos não têm vida própria, sendo eles mesmos a materialização de uma série de negociações $\mathrm{e}$ interesses sociaị desde a sua fase de concepção, transformando e sendo transformados por relações sociais de trabalho na fase de operação das plantas industriais.

No Brasil, o desenvolvimento da Engenharia de Produção e da Ergonomia vem propiciando a incorporação de novos conceitos na compreensão e geração de estratégias integradas de gerenciamento. Contudo, ainda existe um longo caminho a ser percorrido para que se efetive uma cultura técnica das empresas, revertendo a visão ainda hegemônica de que os riscos de acidentes são fatos técnicos e que devem ser restritos as análises de especialistas e as cúpulas gerenciais das empresas. Para tanto, a Engenharia de Produção possui uma responsabilidade particular na difusão de novos conceitos e modelos de análise de causas de acidentes e gerenciamento dos seus riscos, ajudando a sepultar as visões artificiais e desumanas dos atos inseguros e falhas humanas, descontextualizadas dos aspectos gerenciais e organizacionais na 
produção dos acidentes industriais. Do ponto de vista conceitual e metodológico, destacamos a análise do modo real de operação, que inclui o modo degradado de produção e as anormalidades normais, bem como as metodologias participativas de análises de causas de acidentes como centrais na construção de novas práticas de gerenciamento de riscos.

Para avançarmos na superação de alguns dos limites e incertezas presentes nas análises de causas de acidentes, tanto de modo prospectivo como retrospectivo, deve-se considerar que a complexidade das indústrias químicas de transformação não é dada apenas por interações nãolineares de partes e componentes que são altamente acoplados, mas também pelas interações com as relações sociais de trabalho que orientam seu modo real de operação. Isso implica reconhecer:

1) os inerentes limites, incertezas e vieses das análises técnicas de causas de acidentes conduzidas pelos especialistas e sua relação com o gerenciamento de riscos;

2) os limites de cada uma das disciplinas envolvidas na questão das análises de causas de acidentes (Engenharia, Sociologia, Epidemiologia, Psicologia e Ergonomia, entre outras) e a necessidade de sua integração para a construção de abordagens integradoras

3) o conhecimento dos trabalhadores sobre o modo real de operação e a necessidade de que eles participem tanto nas análises de acidentes como na discussão e implementação das estratégias de gerenciamento de riscos, tal como vem sendo atualmente implementado na Suécia (BACKSTRÖM and DÖÖS, 1995).

\section{Referências Bibliográficas}

BACKSTRÖM, T. and DÖÖS, M. The Riv Method: A Participative Risk Analysis: Method and Its Application. WORKSHOP "UNDERSTANDING THE WORK ENVIRONMENT", Stockholm, Swedish Institute for Work Life Research, May 21-24, 1995

DANIELLOU, F. L'Operateur, la Vanne, L'Écran: L'Ergonomie des Salles de Controle. Colletion Outils et Méthods. Montrouge: ANACT, 1986

DUARTE, F.J.C.M.. A Análise Ergonômica do Trabalho e a Determinação de Efetivos: Estudo da Modernização Tecnológica de Uma Refinaria de Petróleo no Brasil. (Tese de Doutorado). Rio de Janeiro: Coordenação dos Programas de Pós-Graduação em Engenharia da Universidade Federal do Rio de Janeiro, 1994

DROGARIS, G. Major Accident Reporting System - Lessons Learned from Accidentes Notified. London: Elsevier, 1993

DWYER, T. Life and Death at Work Industrial Accidents as a Case of Socially Produced Error. New York: Plenum, 1991

FREITAS, C.M. Acidentes Químicos Ampliados - Incorporando a Dimensão Social nas Análises de Riscos. (Tese de Doutorado). Rio de Janeiro: Escola 


\section{PRODUÇÃO}

Nacional de Saúde Pública da Fundação Oswaldo Cruz, 1996.

FREITAS, C.M., PORTO, M.F.S., GOMEZ, C.M. Acidentes Químicos Ampliados - Um Desafio Para a Saúde Pública. Revista de Saúde Pública, vol. 29, p 503-514, 1995

FUNTOWICZ, S. and RAVETZ, J. Science for the Post-Normal Age. Futures, vol. 25, p. 739-755, 1993

GARCIA, R. Interdisciplinariedad y Sistemas Complejos. In: Leff, E. et al. Ciencias Sociales y Formación Ambiental Barcelona, Editorial Gedisa, pp.85-123, 1994

HAGUENAUER, L. O Complexo Químico Brasileiro - Organização e Dinâmica Interna. Rio de Janeiro: Universidade Federal do Rio de Janeiro/ Instituto de Economia Industrial. (texto para discussão $\mathrm{n}^{0} 86$ ), 1986

KUNREUTHER, H.C. and LINERROTH, J. The Framework. In: Kunreuther, H.C. and Linerroth, J. (eds) Risk Analysis and Decision Processes The Siting of Liquefied Energy Gas Facilities in Four Countries. Berlin: Springer-Verlag, pp. 18-31, 1983

KUNREUTHER, H.C. The Prolema. . In: Kunreuther, H.C. and Linerroth, J. (eds) Risk Analysis and Decision Processes - The Siting of Liquefied Energy Gas Facilities in Four Countries. Berlin: Springer-Verlag, pp. 01-17, 1983
LINNEROOTH, J. Risk Analysis in the Policy Process. in: Kunreuther, H.C. and Linerroth, J. (eds) 1983. Risk Analysis and Decision Processes - The Siting of Liquefied Energy Gas Facilities in Four Countries. Berlin: SpringerVerlag. pp. 209-231, 1983

MACHADO, J.M.H. e GOMEZ, C.M. Acidentes de Trabalho: Concepções e Dados. In: Minayo, M.C.S. (org). Os Muitos Brasis - Saúde e População na Década de 80, pp. 117-142, 1995

MACHADO, J.M.H. Violência no Trabalho e na Cidade: Epidemiologia da Mortalidade por Acidente de Trabalho Registrada no Município do Rio de Janeiro entre 1987 e 1988. (Dissertação de Mestrado). Rio de Janeiro: Escola Nacional de Saúde Pública da Fundação Oswaldo Cruz, 1991

MANDL, C. and LATHROP, J. LEG Risk Assessment: Expert Disagree. in: Kunkeuther, H.C. and Linerooth, J. (eds). Risk Analysis and Decision Process - The Siting of Liquefied Energy Gas Facilities in Four Countries. Berlin: SpringerVerlag. pp. 148-172, 1983

MEIRELLES, L.A. e MATTOS, U.A.O. Engenharia Simultânea do Trabalho e do Meio Ambiente: Por Uma Engenharia Total. FIRST INTERNATIONAL CONGRESS OF INDUSTRIAL ENGINEERING and XV ENCONTRO BRASILEIRO DE ENGENHARIA DE PRODUÇÃO, São Paulo, Universidade Federal de São 
Carlos, Anais do XVENEGEP, pp. 203207, 1995

\section{MINISTÉRIO PÚBLICO DO} TRABALHO (MPT). Relatório Sobre Acidentes da Bayer - Fábrica P.U.M. Inquérito Civil Público 10/94. Rio de Janeiro: MPT, 1995

PATÉ-CORNELL, M.E. Learning from the Piper Alpha Accident: A Postmortem Analysis of Technical and Organizational Factors. Risk Analysis, vol. 13, p. 215-232, 1993

PATÉ-CORNELL, M.E. and BEA, R.G. Management Errors and System Reliability: A Probabilistic Approach and Application to Offshore Plataforms. Risk Analysis, vol. 12, p. 01-18, 1992

PERROW, C. Normal Accidents Living with High-Risk Technologies. New York: Basic Book, 1984

PORTO, M.F.S. Trabalho Industrial, Saúde e Ecologia - Avaliação Qualitativa de Riscos Industriais com Dois Estudos de Caso na Indústria Química.. (Tese de Doutorado). Rio de Janeiro: Coordenação dos Programas de Pós-Graduaçãqo de Engenharia da Universidade Federal do Rio de Janeiro, 1994

PORTO, M.F.S. and FREITAS, C.M. Major Chemical Accidents in Industrializing Countries: The SocioPolitical Amplification of Risk. Risk Analysis, vol. 16: 19-29, 1996
RENN, O. Risk Analysis: Scope and Limitations. in: Otway, $\mathrm{H}$. and Peltu, $M$. (eds). Regulating Industrial Risks Science, Hazards and Public Protection. London: Butterworths. p.p. 111-127, 1985

WISNER, A. O Trabalhador Diante dos Sistemas Complexos e Perigosos. in: A Inteligência no Trabalho: Textos Selecionados de Ergonomia. São Paulo: FUNDACENTRO. pp. 53-70, 1994

WYNNE, B. Unruly Technology: Practical Rules, Impractical Discourses and Public Understanding. Social Studies of Science, vol. 18: 147-167, 1988

WYNNE, B. Risk Assessment of Techonological System - Dimensions of Uncertainty. In: Wynne, B. Risk Management and Hazardous Waste Implementation and Dialectics of Credibility. Berlin: Springer-Verlag. P. 356-398, 1987 
Figura 1 - Uso Complementar das Análises de Árvore-de-Falhas e Árvore-de-Eventos

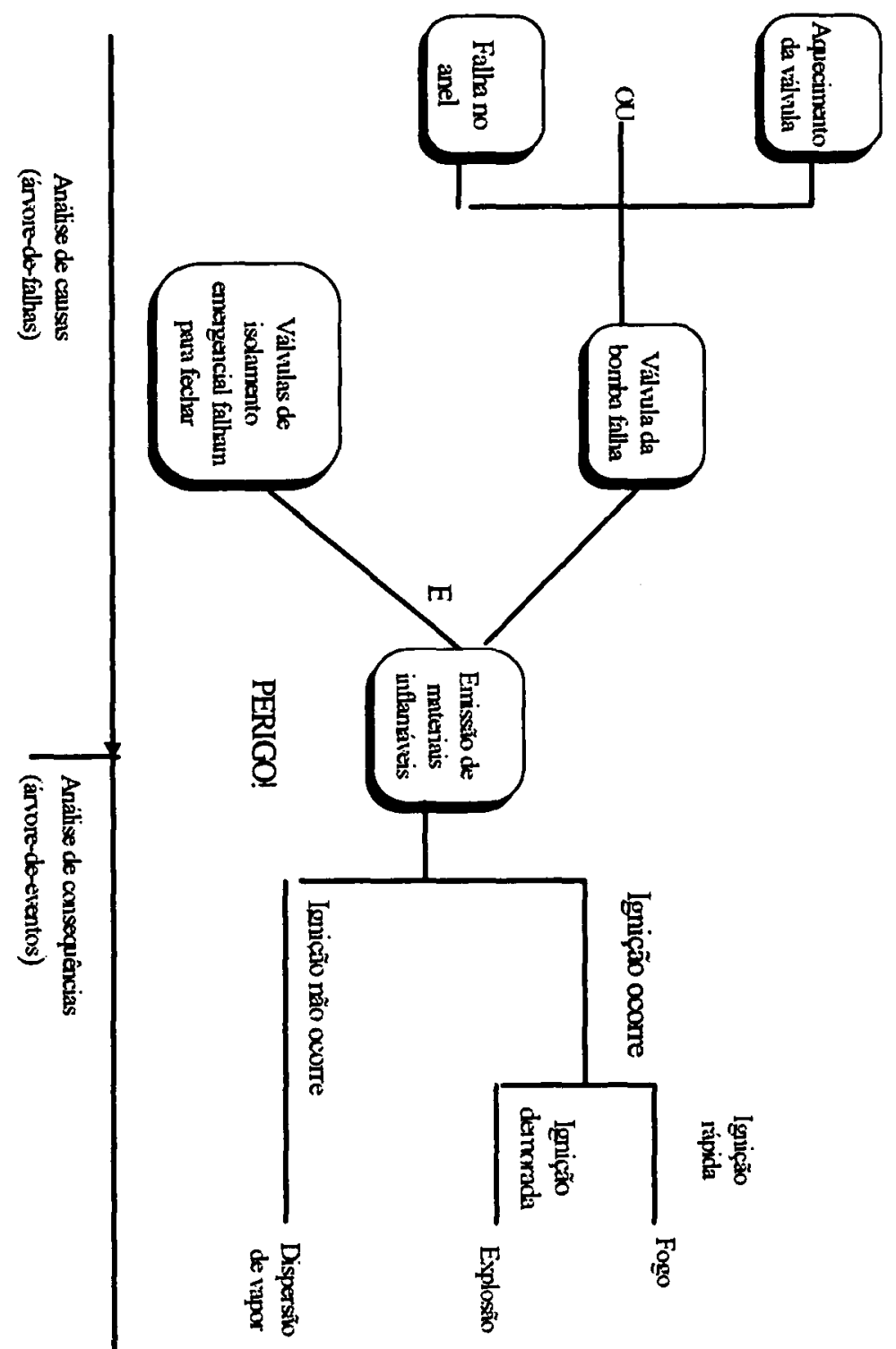

Fonte: Wynne, 1987 
Tabela I - Causas Imediatas dos 121 Acidentes

\section{Notificados}

Causas Imediatas

Número de

Acidentes

I. 1 Erros de operações 28

I.1.1 Operação

I.1.2 Manutenção
21

7

I.2 Falhas nos componentes

I.2.1 Linhas de transferência

I.2.2 Instrumentos /

sistemas de controle / componentes

I.2.3 Válvulas

I.2.4 Maquinaria

1.2.5 Solda

I.3 Corrosão

I.3.1 Corrosão interna

I.3.2 Corrosão externa

I.4 Reações Químicas

I. 5 Carga eletrostática

I. 6 Eventos internos não

conectados com a instalação

I. 7 Eventos externos afetando a instalação

I. 8 Eventos naturais

Sob investigação

25

9

6

6

5

Desconhecidas

7

4

25

6

Nenhum 
Tabela II - Causas Subjacentes dos 121 Acidentes Notificados

Causas Subjjacentes
II.1 Gerenciamento / Omissöes

organizacionais

II.1.4 Procedimentos insuficientes / 62

obscuros

II.1.9 Relacionados à inadequacidade $\quad 54$

do projeto

II.1.1 Falta de informação sobre $\quad 14$

segurança

II.1.7 Treinamento insuficiente do 11

operador

II. 2 Inadequacidade do projeto

II.2.2 Processo inadequadamente

analisado

II. 2.5 Códigos providenciados somente 30

para proteção limitada

II.2.3 Erro de projeto

15

II.3 Abreviamento de procedimentos

II.3.1 Procedimentos operacionais não

7 foram seguidos

Sob investigação

Desconhecido

Fonte: Drogaris, 1993. 
Tabela III - Causas Subjacentes dos Acidentes para os Quais a Falha de Componente Foi Identificada entre as Causas Imediatas ( 54 Acidentes )

\begin{tabular}{|c|c|c|}
\hline \multirow{2}{*}{$\begin{array}{l}\text { Causas subjacentes } \\
\text { II.1 Omissões gerenciais / organizacionais }\end{array}$} & \multicolumn{2}{|c|}{ Número de } \\
\hline & & $44(81 \%)$ \\
\hline II.1.4 Procedimentos obscuros / & $31(57 \%)$ & \\
\hline insuficientes & $28(52 \%)$ & \\
\hline $\begin{array}{l}\text { II. } 1.9 \text { Relacionados à inadequacidade } \\
\text { do projeto }\end{array}$ & $11(20 \%)$ & \\
\hline $\begin{array}{c}\text { Outros } \\
\text { II.2 }\end{array}$ & & $37(69 \%)$ \\
\hline II.2.2 Processo analisado & $22(44 \%)$ & \\
\hline $\begin{array}{l}\text { inadequadamente } \\
\text { II.2.5 Códigos providenciados para }\end{array}$ & $17(31 \%)$ & \\
\hline $\begin{array}{l}\text { proteção limitada } \\
\text { Outros }\end{array}$ & $16(30 \%)$ & \\
\hline II. 3 Abreviamento de procedimentos & & $3(6 \%)$ \\
\hline
\end{tabular}

Fonte: Drogaris, 1993. 
Tabela IV - Causas Subjacentes dos Acidentes para os Quais a Falha do Operador Foi Identificada entre as Causas Imediatas ( 28 Acidentes )

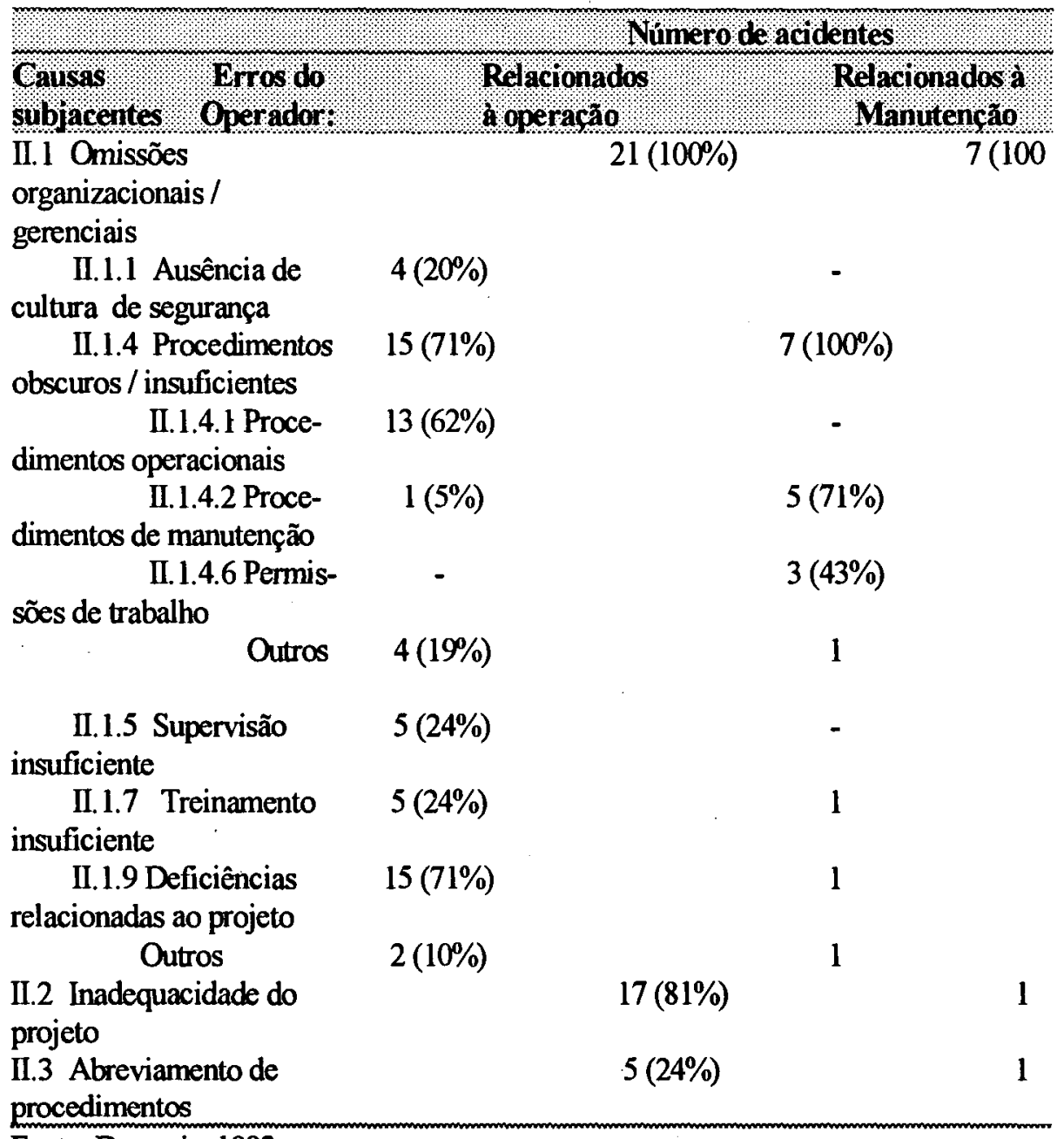

Fonte: Drogaris, 1993. 
Tabela V - Síntese dos Acidentes Ocorridos em uma das Unidades de Produção de uma Insdústria Qúlmica Multinacional (Rio de Janeiro) Entre os Anos de 1992 e 1993

\begin{tabular}{|c|c|c|}
\hline Data & Descrkcão Resumida do acidente & Causas e observaç̄os \\
\hline $11 / 02 / 92$ & $\begin{array}{l}\text { Chave soltou ao desconectar mangote chocando contra os lábios } \\
\text { do funcionário. }\end{array}$ & $\begin{array}{l}\text { Foi considerado falta de hábito em segurança e } \\
\text { proposto maior atenção. }\end{array}$ \\
\hline $19 / 04 / 92$ & $\begin{array}{l}\text { Ao término de drenagem do tambor, a mangueira soltou-se do } \\
\text { mesmo chicoteando e lançou um "spray" do produto (mistura de } \\
\text { fenol+xilol+cresol). }\end{array}$ & $\begin{array}{l}\text { Embora o operário desconhecesse a finalidade do } \\
\text { avental em seu armário de EPI, foi considerado } \\
\text { falta de hábito em segurança do acidentado. }\end{array}$ \\
\hline $05 / 07 / 92$ & $\begin{array}{l}\text { Após jornada, funcionário sentiu queimadura na perna, em } \\
\text { função da calça estar suja com produto à base de fenol. }\end{array}$ & Falta de hábito em segurança. \\
\hline $20 / 07 / 92$ & $\begin{array}{l}\text { O funcionário escorregou ao descer escada entre os níveis } 6 \mathrm{~m} \mathrm{e} \\
3 \mathrm{~m} \text {, com inchação no cotovelo. }\end{array}$ & Escada escorregadia pelo desgaste. \\
\hline $04 / 12 / 92$ & $\begin{array}{l}\text { Ao levant ar tambor contendo fenol com a empilhadeira, foi } \\
\text { atingido na perna por respingos, sofrendo queimadura. }\end{array}$ & $\begin{array}{l}\text { Apesar do tambor estar vazando, foi considerado } \\
\text { falta de hábito em segurança por falta de EPI. }\end{array}$ \\
\hline $21 / 01 / 93$ & $\begin{array}{l}\text { Ao realizar limpeza no filtro 5F33 com estopa embebida com } \\
\text { solvente (xilol+dowanol), uma gota atingiu o olho esquerdo, } \\
\text { passando por cima dos oculos de segurança. }\end{array}$ & $\begin{array}{l}\text { Foi considerado falta de hábito em segurança por } \\
\text { uso incotreto de EPI. }\end{array}$ \\
\hline $21 / 01 / 93$ & $\begin{array}{l}\text { O funcionário foi atingido por substância quúmica (de smodur } \\
\text { N } 75 \text { com solventes xilol e dowanol) e teve principio de } \\
\text { conjuntivite, após acionar bomba de filtração, com vazamento no } \\
\text { filtro } 5 \text { F33. }\end{array}$ & $\begin{array}{l}\text { Defeito devido ao uso ou fabricaçāo do filtro. Foi } \\
\text { proposto revisăo dos procedimentos operacionais } \\
\text { com alteração dos limites de pressão. }\end{array}$ \\
\hline $09 / 02 / 93$ & $\begin{array}{l}\text { Após retirar amostra do produto Desmodur } \mathrm{N} \text { a mais de } 100^{\circ} \mathrm{C} \text {, } \\
\text { o frasco estourou, provocando queimadura química e térmica no } \\
\text { braço. }\end{array}$ & $\begin{array}{l}\text { Falta de EPI adequado (luva de cano longo) não } \\
\text { previsto nos procedimentos de retirada da amostra. }\end{array}$ \\
\hline $21 / 03 / 93$ & $\begin{array}{l}\text { Ao retirar amostra do reator } 3 \mathrm{R} 12 \text {, recebeu vapores de gás no } \\
\text { rost o, causando-lhe conjuntivite química. }\end{array}$ & $\begin{array}{l}\text { Foi considerado falta de hábito em segurança e EPI } \\
\text { impróprio, embora recomendação prevesse } \\
\text { mudança de procedimento na operação (uso de } \\
\text { máscara panorânica) }\end{array}$ \\
\hline $01 / 07 / 93$ & $\begin{array}{l}\text { Ao coletar amostra da destilaçăo do Desmodurl } 100 \% \text { no reat or } \\
\text { 5R32, sofreu queimadura devido a alta temperatura do produto. }\end{array}$ & $\begin{array}{l}\text { Considerando falta de hábito em segurança e EPI } \\
\text { impróprio, embora, como no acidente anterior, } \\
\text { fosse proposta mudança de procedimento } \\
\text { operacional, com recomendação de novos EPI's. }\end{array}$ \\
\hline $13 / 07 / 93$ & $\begin{array}{l}\text { Ao transitar à pé, foi atingido pelo pneu da roda traseira do } \\
\text { galeāo. }\end{array}$ & $\begin{array}{l}\text { A oficina central ficou de analisar a roda para } \\
\text { identificação das causas. }\end{array}$ \\
\hline $04 / 08 / 93$ & Ao manusear tambor vazio, este bateu no joelho direito. & $\begin{array}{l}\text { Considerado falta de hábito de segurança, e } \\
\text { recomendada maior atençăo ao trabalho. }\end{array}$ \\
\hline $11 / 09 / 93$ & $\begin{array}{l}\text { Durante purga do filtro, mangueira escapou do tambor em cima } \\
\text { da balança, atingindo o operador a dois metros com o produto } \\
\text { Desmodur } 44 \mathrm{~V} 10 \text {. }\end{array}$ & $\begin{array}{l}\text { Arranjo considerado perigoso, com proposta de } \\
\text { melhoria do sistema de purga do filtro. Além disso, } \\
\text { propós-se revisar a conscientização dos operadores } \\
\text { na descarga dos reatores. }\end{array}$ \\
\hline
\end{tabular}

Fonte: Ministério Público do Trabalho, 1995. 